\title{
Assessing the information seeking behaviour and utilization of rice farmers in the Ejisu-Juaben municipality of Ashanti Region of Ghana
}

Lawrencia Donkor Acheampong* ${ }^{*}$, Benedicta Nsiah Frimpong, Alexander Adu-Appiah, Bright Owusu Asante and Maxwell Darko Asante

\begin{abstract}
Background: A significant gap exists between advances in technologies in agriculture and what Ghanaian farmers practice on their farms. This paper examines rice farmers' information seeking behaviour and the determinants of information utilization at Ejisu-Juaben Municipality of Ashanti region of Ghana.

Methods: Using a two-stage sampling technique, a total of 109 rice farmers were selected for the study. The probit model was used to examine information seeking behaviour and the determinants of information utilization.

Results: The results showed that most of the respondents were literate and relied on interpersonal information sources. The major type of information received was on agronomic practices, and majority of the respondents utilized the information received. Respondents' information seeking behaviour and utilization was found to be high which implied rice farmers are willing to utilize information received to improve their productivity and incomes. The results further signify that to enhance the use of information among farmers for relevant production activities such as fertilizer application, pesticide application, disease and weed control will require investments in extension services, increasing farmers' access to education, targeting farmers with larger farm sizes, and higher rice yields. These factors have the potential to enhance information seeking and utilization for enhanced rice productivity in Ghana. Majority of the respondents are willing to pay for their preferred information needs. The constraints limiting rice farmers' information seeking behaviour and utilization were the inadequate extension agents and lack of agricultural information services in the communities.
\end{abstract}

Conclusion: It is recommended that the Government improve access to extension services by employing more extension workers to provide the necessary training support to farmers.

Keywords: Rice production, Information seeking behaviour, Ghana, Information sources

\section{Background}

The present age has been rightly called an Information Age because information has become the most important element for progress in society. Information has been described as "the fifth need of man ranking after air, water, food and shelter" [1]. Everyone needs information about everything even in his day-to-day life.

\footnotetext{
*Correspondence: lawdonkor@gmail.com
} CSIR- Crops Research Institute, Kumasi, Ghana
In agricultural production environment, relevant and timely information helps farming communities to take right decisions. Utilization of information in the agricultural sector enhances farming productivity in a number of ways. Providing information on weather trends, best practice in farming, new technologies developed by scientists, and timely access to market information helps the farmer make correct decisions about what crops to plant and where to sell their product and buy inputs [2]. Ghana is an agriculture-based country with farming and related 
activities constituting about 20.3\% of Gross Domestic Product (GDP) and employment [3].

Agricultural information is useful for farmers because it helps them to overcome their inadequacies in knowledge of certain basic practices that may include technical, marketing, social, and legal agricultural information [4]. Farming is one profession that depends on the constant flow of information. However, most farmers find it difficult to identify when they have the need for information. Again, in most parts of Ghana, especially in the Ashanti Region, there are few information centres where farmers may resort to meet their information needs. Where these centres are available, they are not well resourced with best materials and personnel who can professionally handle these farmers most of whom are illiterates.

This disturbing development has made most farmers to depend more on informal and less reliable sources like their friends, traditions handed over to them from generations for their information needs. Reliance on such unpredictable sources has always led to appalling results such as low yielding, poor harvesting techniques, bad financial and credit decisions. This has always led to these farmers failing to meet their target output/production.

Rice (Oryza sativa L.) is quickly becoming a major staple food for urban and rural consumers [5]. However, domestic consumption of rice in Africa is significantly greater than domestic production, necessitating increased imports that drain large amounts of scarce foreign exchange. Currently, the demand for rice in subSaharan Africa (SSA) is double the rate of population growth and consumption is growing faster than production. Across Africa, local production has been unable to keep pace with the rate of increase in demand. In the past 50 years, rice production in Africa has increased to 14.60 million tons (from about 3.14 million metric tons) and most of the increase in production has come from expansion in the area devoted to the crop rather than from increases in yields. During the same period, Asia has increased rice production on a much greater scale, to about 570 million tons (up from 200 million tons), with most of this coming from higher yields on existing farmland $[6,7]$.

In Ghana, the total rice consumption in 2005 amounted to about 500,000 tons which is equivalent to per capita consumption of $22 \mathrm{~kg}$ per person [8,9]. Ghana depends largely on imported rice to make up the deficit in rice supply. On average, annual rice import is 400,000 tons. The self-sufficiency ratio of rice in Ghana has declined from $38 \%$ in 1999 to $24 \%$ in 2006 [10, 11]. The rice import bill is estimated at US $\$ 500$ million annually and has become a source of concern to government.

Improvement in rice productivity potential will therefore play a critical role in feeding the Ghanaian population that is expected to double during the next two decades. Therefore, there is a need to support farmers to increase rice productivity rather than acreage cultivated, if Ghana is to meet the shortfall in rice production. Among the challenges that national policies should address is access to and use of improved technologies. If the negative productivity effects are to be reversed, new and existing technologies must be quickly up-scaled and out-scaled. This cannot be achieved unless the relevant information is provided to farmers in a timely manner.

Information source is an institution or individual that creates or brings about a message [12]. The characteristics of a good information source are timelessness, accuracy, relevance, cost effectiveness, trustworthiness, usability, exhaustiveness and aggregation level [12]. The selection of an information source depends on a number of factors, including level of income, farm size, age, geographical location, level of education [13]. Using the Indian NSSO 2003 survey, [14] found that small and marginal farmers accessed less information and from fewer sources than medium- and large-scale farmers [15]. Another study by [16] reported farmers use agricultural extensions officers, posters, televisions and radio as their source of their information.

Other authors reported that sources of information used by rice farmers were personal experience, workshops and seminars, training sessions, friends and neighbours, Ministry of Agriculture, magazines of agriculture, extension officers, local Government officers, non-Government organization, libraries of agriculture and posters [15]. Therefore, in view of the fact that each farmer prefers certain information sources or channels to others, it is important to do a thorough study before opting for an information source or channel to address their needs.

Farmers require different types of information for their day-to-day agricultural activities. A study by [17] found that the important information needs for rice farmers were pest and disease management, pesticide and fertilizer application, best time to plant, planting method, storage and seed treatment.

Farmers face several challenges in accessing agricultural information. For instance, [18] identified that some of the challenges farmers face in accessing agricultural information were outdated information, language barrier, lack of awareness on existence of different information sources, lack of funds to acquire information and poor format of information carrier. The findings from the referred study show that poor/unreliable information, infrastructure, high illiteracy levels, low income, lack of electricity and high cost of ICTs have limited the accessibility of information services in rural areas.

According to [19], the information needs of farmers change from time to time due to changing needs on 
emerging issue in agricultural technologies and innovations, environmental changes and agricultural policies. Yet, there is inadequate information for rice farmers. The main problem is where to locate and how to evaluate the information. This problem is not only limited to rice farmers at Ejisu-Juaben Municipal in Ashanti Region, Ghana but most farmers in Africa face similar challenge. A better understanding of farmers' information needs and information sources could help guide extension and other agricultural programs to better target specific groups of farmers for appropriate interventions [17]. This paper seeks to address this issue. Specifically, the paper identifies the information needs of the rice farmers and sources of information available to them, and it further determines the information seeking behaviour and use of information among rice farmers and whether the rice farmers are willing to pay for their most preferred information, and finally, identifies the constraints facing rice farmers in the study area.

\section{Research methodology}

\section{Study area and sampling techniques}

The study was conducted in the Ejisu-Juaben Municipality of Ashanti region of Ghana. This Municipality was selected purposively due to the importance of rice production and rice research activities in the area [18]. In addition, farming is the major occupation of the majority of the residents of this Municipality; hence, the need of bridging the information gap for these farmers is essential for enhanced productivity and incomes. A two-stage sampling technique was used to draw the sample. First, the Municipality and communities were purposively selected. This was followed by a random sampling of the farmers from a list of rice producing farmers in the sampled communities in the Municipality. Five communities were selected based on the volumes of rice produced within the district. The identification of the communities was based on discussions with the Municipal Director of Agriculture (MDA) and local extension officers in the district. The selected communities were Besease, Nobewam, Duampompo, Donaso and Bomfa. In all, a total of one hundred and nine farmers were drawn from the communities.

\section{Data collection procedures and analysis}

The study employed both qualitative and quantitative approaches with the former being dominant because of its usefulness in studying human action in a natural setting and in attempting to make sense of, or interpret, phenomena in terms of the meanings people bring to them [19]. Primary data as well as secondary information were collected during the study. The secondary information included desk reviews, searching through the internet and the libraries for similar works in the area. The primary data were collected through the administration of a structured interview schedule to all the respondents. Descriptive and inferential statistics tools were used to analyse the data collected.

Descriptive statistics such as frequency counts, percentages, charts were used to analyse and summarize the results. The probit model was used to examine the determinants of information utilization among sampled rice farmers. Data were analysed using the Statistical Package for Social Sciences (SPSS) version 20 and the STATA software version 14 .

\section{Analytical framework for estimating the determinants of information usage}

The use of information by farmers was modelled as a household production decision-making process which is rooted on the utility maximization theory [20], where a farmer uses the information received only when the utility obtained from using the information is greater than the utility he obtains from not using it. Consequently, this decision is a binary involving two mutually exclusive alternatives. The farmer either uses the information or does not. This yields a binary dependent variable, $Y_{i}$, which takes on the values of 0 if he/she does not use the information obtained and 1 if the information is used. Thus, to observe a value of 1 will result in the probability,

$$
P_{r}=\left(Y_{i}=1 / x_{i} \beta_{i}\right)=1-F\left(-x_{i} \beta_{i}\right)
$$

and that for observing 0 is given by,

$$
P_{r}=\left(Y_{i}=0 / x_{i} \beta_{i}\right)=F\left(-x_{i} \beta_{i}\right)
$$

where $F$ is a continuous and strictly increasing cumulative distribution function, which takes a real value and returns a value which ranges from 0 to 1 .

Consequently, the parameters in the models in Eqs. (1) and (2) are obtained using the maximum likelihood estimation approach. The dependent variable is an unobserved latent variable that is related to $Y_{i}$ as

$$
Y_{i}=\beta_{j} X_{j i}+\delta_{i}
$$

where $\delta_{i}$ is a random disturbance term.

The observed dependent variable is determined by whether the predicted $Y_{i}^{*}$ is greater than 1 or otherwise:

$$
Y_{i}=1 \quad \text { if } Y_{i}^{*}>0 \text { and } Y_{i}=0 \text { if } Y_{i}^{*} \leq 0
$$

where $Y_{i}^{*}$ is the threshold value for $Y_{i}$ and is assumed to be normally distributed.

Following from Madala (2005), the probit model adopted for the study is specified as:

$$
P_{i}=P\left(Y_{i}^{*}<Y_{i}\right)=P_{i}=P\left(Y_{i}^{*}<\beta_{0}+\beta_{j} X_{j i}\right)
$$


where $P_{i}$ is the probability that an individual will make a certain choice (to use the information received or not) and $Y_{i}$ is the dependent variable.

\section{The empirical model}

The empirical model is explicitly specified as:

$\operatorname{Pr}_{i}\left(\operatorname{Iuse}_{i}=1 \mid x\right)=\alpha_{0}+\sum_{J=1}^{5} \alpha_{H, j} H_{k, i}+\sum_{J=1}^{3} \alpha_{X, j} X_{j, i}+\sum_{J=1}^{5} \alpha_{I, j} I_{j, i}$

where $H_{k, i}$ is a set of covariates that represent the characteristics of the sampled households and their respective socio-economic conditions; $X_{k, i}$ represents farm-level factors; $I_{k, i}$ denotes the set of institutional covariates of the rice farmers.

\section{Results and discussion}

\section{Socio-demographic characteristics of respondents}

Table 1 shows the demographics characteristics of the respondents. The gender distribution shows that men dominate rice farming. The dominance of men may be due to the tedious nature of rice production activities. Similar studies have reported male dominance in agriculture $[4,17]$. However, it is worth noting that onethird of the respondents who owned rice farms and were women. Any technology that is therefore targeting

Table 1 Demographic characteristics of respondents. Source Survey, 2015

\begin{tabular}{|c|c|c|}
\hline Variables & Frequency & Percentage \\
\hline \multicolumn{3}{|l|}{ Sex } \\
\hline Male & 73 & 67 \\
\hline Female & 36 & 33 \\
\hline \multicolumn{3}{|l|}{ Marital status } \\
\hline Married & 99 & 90.8 \\
\hline Single & 4 & 3.7 \\
\hline Widowed & 3 & 2.8 \\
\hline Divorced & 3 & 2.8 \\
\hline \multicolumn{3}{|l|}{ Educational level } \\
\hline None & 34 & 31.2 \\
\hline Basic & 60 & 55.0 \\
\hline Secondary & 15 & 13.8 \\
\hline Membership of agricultural organization & 23 & 21.1 \\
\hline Membership of rice-based organization & 16 & 14.7 \\
\hline \multicolumn{3}{|l|}{ Benefits derived from organization } \\
\hline Access to credit & 10 & 9.2 \\
\hline Access to inputs & 8 & 7.3 \\
\hline $\begin{array}{l}\text { Technical advice and training on agronomic } \\
\text { practices }\end{array}$ & 5 & 4.6 \\
\hline Willingness to pay for information & 91 & 84 \\
\hline
\end{tabular}

rice production in Ghana should be gender sensitive. Majority of the respondents, $91 \%$ were married. This is a proxy for the labour support rice farmers may get from their spouses for farm activities and their access to some important production resources. The majority of respondents being married may mean that rice plays an important role in supporting the family's welfare. However, this may slow down the decision-making process in accessing and utilizing information as members of the family may have to be consulted before adopting and utilizing information. Majority of the respondents have had between 6 and 12 years (Table 2) of formal education with about 55\% falling within the basic level. About 31\% of farmers had no formal education (Table 1). All things being equal, the level of formal education is expected to positively affect the farmer's ability to access extension information as well as improve their knowledge on rice production technologies, trade and marketing information. Their literacy level will also boost their capacity to utilize information, which will improve rice production.

Farmers' based organizations have been identified as an effective channel of information to farmers [3, 21, 22]. Out of the 109 respondents, only 16 farmers representing about $15 \%$ belonged to rice-based organization (Table 1) and this could affect their access to information and information seeking behaviour especially on rice. The benefits they have derived from being part of an agricultural association are their access to credit, inputs and technical advice as well training on agronomic practices as presented in Table 1. With these benefits, it puts the majority who do not belong to any association and have no access to information at a great disadvantage. There is the need to encourage farmers to form groups to benefit from information on rice to improve their productivity.

Though majority of the respondents were literate up to basic-level Junior High School (JHS) as in the qualitative analysis, the years in school depicts that the educational background is skewed towards the primary

Table 2 Summary statistics of quantitative variables. Source Survey, 2015; exchange rate: $\$ 1=\mathbf{G H} \mathbb{3} 3.80$

\begin{tabular}{|c|c|c|c|c|}
\hline Variable & Minimum & Maximum & Mean & SD \\
\hline Age & 21 & 72 & 40.4 & 10.8 \\
\hline Years in rice farming & 1 & 45 & 8.5 & 8.6 \\
\hline Years of schooling & 0 & 12 & 5.7 & 4.6 \\
\hline Household size & 1 & 15 & 6.4 & 2.9 \\
\hline $\begin{array}{l}\text { Household members active in } \\
\text { rice cultivation }\end{array}$ & 1 & 12 & 1.8 & 8.5 \\
\hline Farm size in hectares & 0.2 & 10 & 1.2 & 1.2 \\
\hline Least amount willing to pay $(\$)$ & 0 & 52.63 & 9.2 & 16.63 \\
\hline $\begin{array}{l}\text { Maximum amount willing to } \\
\text { pay }(\$)\end{array}$ & 0.53 & 105.3 & 18.9 & 21.4 \\
\hline
\end{tabular}


level. With a household size of about six members per household, two members in addition to the farmer were actively involved in rice farming (Table 2). This means that the households may have to depend more on hired labour for most of their on farm activities. This is contrary to findings reported by [4], where the authors concluded from their research that because the households had family size of five or more, their farming activities may be dependent on family labour. This could probably be because they failed to probe further about the number of family members actively involved in the rice farming.

With an average age of 40 years, it can be said that most of the farmers are in their middle age and are active in agricultural production. The farm sizes ranged from 0.2 to 10 hectares with an average of $1.2 \mathrm{Ha}$. This confirms studies by [23-25] that majority of farmers in Africa and Asia cultivate less than $2 \mathrm{Ha}$ field.

The top four information types received by rice farmers were good agronomic practices such as pesticide application, fertilizer application, weed control and diseases control measures (Fig. 1). The following were knowledge gaps identified: land preparation, new seeds/ varieties, storage of rice, marketing, agricultural credit and irrigation practices. These are critical resources and knowledge gaps that could affect rice productivity. The knowledge needs varied across the communities sampled based on their interaction to research and other public organizations.

\section{Types of information received by farmers}

The study assessed the level of usage of information received and found out that most of the respondents always utilize the information received (Table 3), although there is still some room for improvement. This implies that if farmers are constantly reached with agricultural information and more specifically information on rice, they will utilize it to improve their productivity and hence their incomes and livelihoods. The least utilized information types were agricultural credit and irrigation. The low response rate for information on irrigation was reported by other authors [26]. For information on agricultural credit, the relatively lower utilization may be due to the high interest rates and general difficulties that farmers face in accessing credit for agriculture in Ghana because the banks see it as a high-risk business.

\section{Information sources and preferences by rice farmers}

The various sources of rice information available to farmers are shown in Table 4. Majority of the farmers relied on their personal experience, family members and

Table 3 Distribution of the utilization of information received. Source Field survey, 2015

\begin{tabular}{llll}
\hline Information type & \multicolumn{3}{l}{$\begin{array}{l}\text { Percent utilization of information } \\
\text { among rice farmers }\end{array}$} \\
\cline { 2 - 4 } & Never use & Rarely use & Use always \\
\hline Marketing information & 3.7 & 8.3 & 31.2 \\
Agricultural credit information & 2.8 & 20.2 & 13.8 \\
Fertilizer application & 4.6 & 13.8 & 55.0 \\
Pesticide application & 3.7 & 13.8 & 58.7 \\
Weed control & 5.5 & 11.0 & 56.9 \\
Disease control & 4.6 & 17.4 & 45.9 \\
Storage information & 6.4 & 11.0 & 26.6 \\
Land preparation & 8.3 & 8.3 & 32.1 \\
New seeds & 3.7 & 15.6 & 27.5 \\
Irrigation & 6.4 & 10.1 & 8.3 \\
\hline
\end{tabular}

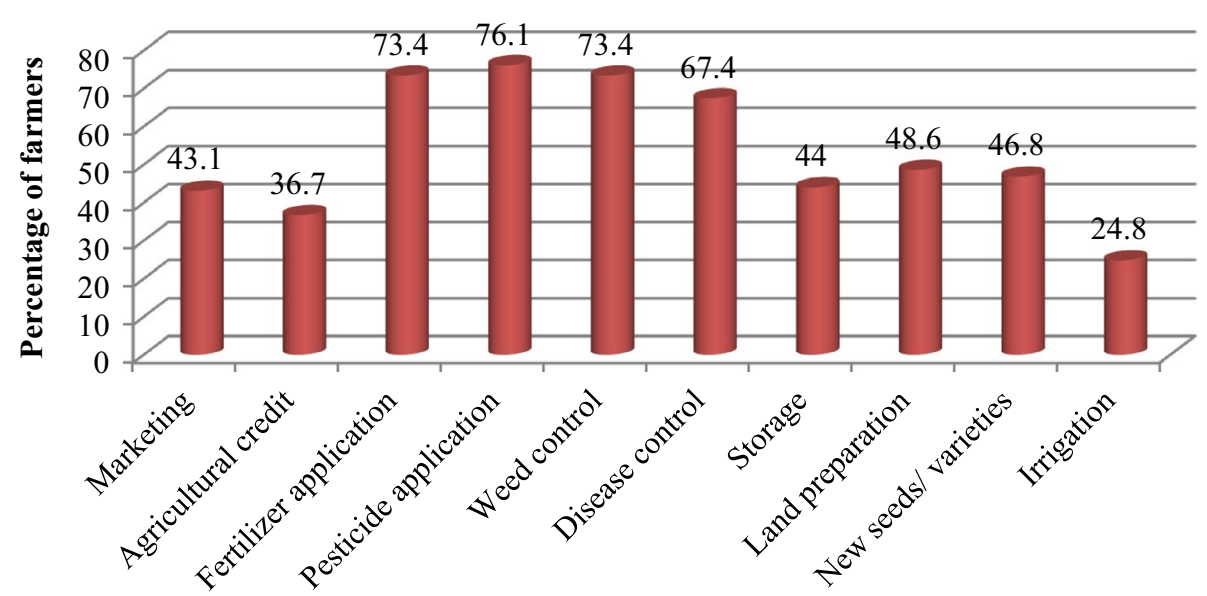

Types of rice information received

Fig. 1 Types of information received by farmers 
friends for information. Lwoga et al. [26] reported similar information sources for farmers. Many of the farmers do not obtain information from either extension or radio. This was due to the fact that majority did not even know their extension agents and were also unaware whether the radio stations aired any agricultural programs. Other studies indicated that information seeking through radio is a very effective medium of disseminating new agricultural innovations and marketing information to farmers $[4,27$,$] . This is because it is the cheapest and$ quickest means of passing information to farmers [28]. Extension agents as well as other agricultural institutions must communicate and disseminate information to farmers using this medium since most rural farmers in Ghana own radios.

In analysing respondents preferred information sources in terms of their credibility, the sources in order of preference were friends/fellow farmers, family members, radio, extension and personal experience. This result confirms why "poor knowledge-sharing culture was not a severe constraint for farmers because they already receive information from fellow farmers".

It was also found that $90 \%$ of the respondents have high level of information seeking behaviour and utilization. This implies that rice farmers are willing to seek and utilize information that will enhance their productivity and improve their living standards. Similar findings were made in other studies [4].

\section{Determinants of information utilization among rice farmers in Ghana}

Considering the high extent of use of the information obtained by farmers on certain crop production practices such as fertiliser application, weed control, disease control, and pesticide application, this paper goes a step further to examine what the key drivers are among the farmers on the use of such information obtained. The probit results of the determinants of information utilization among the sample farmers are presented in Table 5. The results indicate that the factors considered had varying effects on the different types of information use among the farmers.

Table 4 Respondents' information sources and preferences. Source Field survey, 2015

\begin{tabular}{llll}
\hline Information sources & Frequency & Percentage & $\begin{array}{l}\text { Preferred } \\
\text { source (\%) }\end{array}$ \\
\hline Family & 55 & 48.6 & 44.1 \\
Radio & 42 & 38.5 & 38.5 \\
Personal experience & 67 & 61.5 & 32.0 \\
Friends & 58 & 53.2 & 49.6 \\
Extension & 39 & 35.8 & 34.9 \\
\hline
\end{tabular}

The utilizations of all the four types of information are determined by farmers' access to extension services and were highly significant at the $1 \%$ level. However, the magnitudes of the effects do vary across information types. For instance, having access to extension services increases the probability of farmers' utilization of information for fertilizer application by 33.50 , whereas those for pesticide application, disease control and weed control are 39.09, 37.63 and 25.49, respectively. This suggests that, largely, access to extension tends to have a significantly higher influence on the use of information for pesticide application than the remaining information usage among the farmers, whereas the least effects were found with weed control. This is not surprising since pesticides application is very crucial for enhancing rice productivity and hence requires critical attention for effective results. Language use and distance to information source significantly influenced information utilization for both pesticide and fertilizer application only. However, whilst the distance had a positive effect, the marginal effect of language use was negative and also the effects tend to be greater for fertilizer application than for distance to information source. The implication is that farmers who are farther away from information sources are more likely to use information for fertiliser and pesticide application than their counterparts at close proximities to the information source. As expected, since those farther from the source may not have easy access to the source, their desire to obtain the necessary information relevant for their production is very important to them and this could account for this finding. This corresponds with the findings of [29], where information needs and information seeking behaviour of small-scale farmers in Tanzania were negatively influenced by distances to information sources.

It is worth noting that albeit language use was significant only in information use for pesticide and fertiliser application only, it was negative across all the usage type. The negative effect of language usage implies that the types of language used in the information dissemination decreased the use of information for pesticides and fertilizer application. This suggests that the type of language could be a great barrier to effective information dissemination and hence could affect information utilization negatively. Similar results have been obtained in [30, 31]. Besides extension, information use for weed control was also positively and significantly influenced by gender and yield. This implies that being a male and increase in rice yield increases the probability to use information for weed control purposes among the farmers. From the socio-cultural perceptive, generally, in the study area, male farmers tend to have access to basic production resources and also play a key role in controlling weeds 
Table 5 Probit estimates of the determinants of information utilization among rice farmers in Ghana

\begin{tabular}{|c|c|c|c|c|c|c|c|c|}
\hline \multirow[t]{3}{*}{ Variables } & \multicolumn{8}{|c|}{ Types of information utilization among rice farmers } \\
\hline & \multicolumn{2}{|c|}{ Fertilizer application } & \multicolumn{2}{|c|}{ Pesticide application } & \multicolumn{2}{|c|}{ Disease control } & \multicolumn{2}{|c|}{ Weed control } \\
\hline & ME & SE & ME & SE & ME & SE & ME & SE \\
\hline Age & 0.0279 & 0.0285 & 0.0305 & 0.0267 & 0.0221 & 0.0277 & 0.0256 & 0.0266 \\
\hline $\mathrm{Age}^{2}$ & -0.0003 & 0.0003 & -0.0003 & 0.0003 & -0.0003 & 0.0003 & -0.0003 & 0.0003 \\
\hline Gender & -0.0601 & 0.0966 & 0.0664 & 0.0955 & -0.0066 & 0.1095 & $0.1844^{* *}$ & 0.1060 \\
\hline Years of schooling & 0.0092 & 0.0116 & $0.0225^{* *}$ & 0.0109 & 0.0006 & 0.0120 & 0.0112 & 0.0114 \\
\hline Econ. active $\mathrm{HH}$ & -0.0242 & 0.0283 & $-0.0581^{* *}$ & 0.0288 & $-0.0728^{* *}$ & 0.0341 & -0.0158 & 0.0296 \\
\hline Experience in rice production & 0.0071 & 0.0066 & 0.0006 & 0.0058 & $0.0150^{* *}$ & 0.0072 & 0.0001 & 0.0061 \\
\hline Distance to the information source & $0.3181^{* * *}$ & 0.0761 & $0.2509^{* *}$ & 0.0723 & 0.1743 & 0.1191 & 0.1474 & 0.1142 \\
\hline Language used in & $-0.3494^{* *}$ & 0.1825 & $-0.3295^{* *}$ & 0.1759 & -0.1268 & 0.1542 & -0.2248 & 0.1578 \\
\hline Land & $0.0317^{*}$ & 0.0169 & 0.0144 & 0.0145 & 0.0158 & 0.0175 & 0.0311 & 0.0201 \\
\hline Yield & $0.0004^{* *}$ & 0.0002 & 0.0004 & 0.0002 & 0.0003 & 0.0002 & $0.0004^{* *}$ & 0.0002 \\
\hline Extension & $0.3350^{* * *}$ & 0.0950 & $0.3909^{* * *}$ & 0.0881 & $0.3763^{* *}$ & 0.1018 & $0.2549 * *$ & 0.1026 \\
\hline FBOs & 0.2556 & 0.0827 & 0.0944 & 0.1002 & -0.0855 & 0.1379 & -0.1903 & 0.1374 \\
\hline Market information & 0.1382 & 0.1130 & 0.1454 & 0.1083 & 0.1053 & 0.1190 & -0.0754 & 0.1127 \\
\hline Constant & -3.7439 & 2.2778 & $-4.1655^{*}$ & 2.5153 & -1.9605 & 1.9590 & -2.2108 & 2.0028 \\
\hline Observed $\operatorname{Pr}$ & 0.6880 & & 0.7248 & & 0.6330 & & 0.6789 & \\
\hline PredictedPr(@mean values) & 0.7548 & & 0.8016 & & 0.6616 & & 0.7127 & \\
\hline Pseudo- $R^{2}$ & 0.2511 & & 0.2948 & & 0.1645 & & 0.1639 & \\
\hline Loglikelihood & -50.67 & & -45.23 & & -59.86 & & -57.20 & \\
\hline Lrchi (13) & $33.97^{* * *}$ & & $37.81^{* * *}$ & & $23.57^{* * *}$ & & $22.43^{* * *}$ & \\
\hline No. of observations & 109 & & 109 & & 109 & & 109 & \\
\hline
\end{tabular}

using various approaches and hence are more likely to use information on weed control. Similar effect of yield is also found with information use for fertiliser application. Rice land had a significant positive effect on information utilization for fertilizer application only, suggesting that farmers with larger rice plots tend to make good use of information on fertilizer application than those with smaller rice land sizes. As a consequence, such farmers are able to effectively apply fertilizers to their land in order to obtain the best from their farming activities.

Also with larger farm sizes, farmers need to be all equipped with an effective fertiliser use for enhanced productivity and hence are more likely to effectively use information on fertilizer application. The result further shows that farmers with larger active household member are less likely to use information for both pesticide application and disease control. This might be because the availability of economically active household members is not only a good source of household labour for pesticide application and disease control but is also a form of social capital for the household and potential sources of incomes to the households especially when they are involved in off-farm income generation activities. As expected, farmers with more years of schooling were able to effectively use information for pesticide application.
This is not surprising at all because besides obtaining the information on pesticide application, educated farmers tend to better assimilate and apply the information obtained than their counterparts who are not educated.

\section{Constraints to information seeking}

Several constraints have been found in the literature to be militating against farmers' agricultural information seeking behaviour and those relating to rice were put before the farmers to confirm their level of severity on a 3-point scale (Table 6). The major constraint was the inadequate extension agents followed by lack of information services as also identified by [25]. It is therefore recommended that more extension agents been employed and resourced so that they can expand their operations to resource poor farmers.

\section{Preferred information needs by rice farmers}

The following information needs were elicited from the respondents as areas where they need training Information on bird control, pesticide application, efficient use of fertilizer and other chemicals, identification of diseases and pests, marketing issues, access to improved seeds and planting methods. These results accord with those of similar studies where these information needs were identified by farmers $[17,18,26]$. 
Table 6 Constraints to respondents' information seeking behaviour. Source Field survey, 2015

\begin{tabular}{|c|c|c|c|}
\hline \multirow[t]{2}{*}{ Constraints } & \multicolumn{3}{|c|}{ Severity of the constraint } \\
\hline & Most severe & Severe & Not severe \\
\hline Lack of information services & 37.6 & 10.1 & 52.3 \\
\hline Lack of relevant materials in offices and libraries & 8.3 & 11.9 & 79.8 \\
\hline Inadequate number of extension agents & 42.2 & 11.9 & 45.8 \\
\hline Lack of awareness of information sources & 22.9 & 12.8 & 63.2 \\
\hline Current information outdated & 11.0 & 14.7 & 74.3 \\
\hline Information not easily accessible & 13.8 & 12.8 & 73.3 \\
\hline Poor knowledge-sharing culture & 26.6 & 8.3 & 65.1 \\
\hline Time constraint & 17.4 & 12.8 & 69.8 \\
\hline Language barrier & 11.0 & 8.3 & 80.7 \\
\hline Long distances to information centre & 11.0 & 11.0 & 78.0 \\
\hline Socio-economic and social factors (e.g. Age, marital status, etc.) & 25.7 & 0 & 74.3 \\
\hline
\end{tabular}

\section{Farmers' willingness to pay for preferred information}

The respondents' opinions were elicited on their willingness to pay for their preferred information. Majority of them $(84 \%)$ were willing to pay as indicated on Table 1. The amount they are willing to pay ranged from an average minimum of $\$ 9$ to an average maximum of $\$ 19$ (Table 2). The farmers explained that the amount they were willing to pay would depend on the content of the training, the training duration and the time within the season when training is organized. For those who needed information to improve their productivity but were not willing to pay for it attributed it to financial constraints and appealled to government to pay resource persons to offer such trainings.

\section{Conclusion, recommendations and implications}

The study revealed that rice farmers relied on interpersonal sources of information. They least trusted their personal experience as they admitted they could not depend on it if they have to improve the level of productivity. Most of the information received and utilized were on agronomic practices with less information received on post-harvest activities. There was subtantial information gap on marketing and irrigation among the farmers. In order to improve farm incomes and achieve food security, these two issues are critical. Agricultural extension agents must include the post-harvest issues in their training package so that farmers can be effective at each stage of their production. Majority of the respondents had high information seeking behaviour and utilization which implies their willingness to seek and use information for enhanced productivity.

The major constraints identified were inadequate extension agents and lack of information service centres. It is thus important for Government to improve access to extension services by employing more extension staff. The Departments of Agriculture especially in the districts must employ the use of multiple information sources and other strategies to deliver relevant agricultural information to farmers in rural communities. The E-extension programme introduced must incorporate all aspects of production and be scaled up to rural communities since most of the farmers living in rural communities own cell phones.

The results further highlight the important factors that could drive information seeking and utilization among rice farmers in Ghana. Enhancing the use of information among farmers for relevant production activities such as use of certified improved seed, fertilizer application, pesticide application, and disease and weed control will require investments in extension services, increasing farmers' access to education, farmers with larger farm sizes, and with higher yields. These factors have the potential to enhance information seeking and utilization for increased rice productivity in Ghana and West Africa.

\section{Authors' contributions}

LDA was the lead investigator and the initiator of the study also responsible for literature search and write-up. LDA, BNF and AAA were responsible for the study design, data collection and preparing the manuscript. MDA was responsible for the overall study design and provided critical feedback on the manuscript. AAA, BOA and BNF did the data entry, analysis and discussion. All authors read and approved the final manuscript.

\section{Acknowledgements}

We thank rice farmers in the studied communities who participated in the study. We also wish to express our gratitude to the Municipal Director of Agriculture (MDA) and local Extension staff at the study area who assisted us during the data collection. We also acknowledge KAFACI-Rice project for funding the research.

Competing interests

The authors declare that they have no competing interests. 


\section{Consent for publication}

All authors agree and consent for the article to be published.

\section{Ethical approval and consent to participate}

Oral informed consent was obtained from each respondent from each of the participating households.

\section{Funding}

The funding for this study was provided by Korea-Africa Food and Agriculture Cooperation Initiative (KAFACI).

\section{Publisher's Note}

Springer Nature remains neutral with regard to jurisdictional claims in published maps and institutional affiliations.

Received: 4 November 2016 Accepted: 28 March 2017

Published online: 01 August 2017

\section{References}

1. Kemp DA. Nature of knowledge: and introduction for librarians. London: Clive Bingley; 1976.

2. Bachhv NB. Information needs of the rural farmers: a study from Maharashtra India a Survey. Lib Philos and Pract. 2012 Available http://digitalcommons.unl.edu/cgi/viewcontent.cgi?article=2043\&content=libphilp arc. Retrieved: 30/10/16.

3. Institute of Statistical. Social and economic research (ISSER) The State of the Ghanaian Economy. Legon, Accra: University of Ghana; 2013.

4. Owolade EO, Kayode Arimi. Information-seeking behaviour and utilization among snail farmers in Oyo State, Nigeria: implications for Sustainable. Anim Prod. 2012. doi:10.5191/jiaee.2012.19304.

5. Nwanze KF, Mohapatra S, Kormawa P, Shellemiah K, Bruce-Oliver S. Rice development in Sub-Saharan Africa. J Sci Food Agric. 2006;68:675-7.

6. Norman JC, Otto E. Sustainable rice production for food security. In: Proceedings of the 20th Session of the International Rice Commission, Bangkok, Thailand, 2002. 23-26 July 2002. International Rice Commission.

7. African Rice Center (WARDA) Africa Rice Trends: Overview of recent developments in the sub-Saharan Africa rice sector. 2007. Africa Rice Center Brief, Cotonou, Benin, p. 10.

8. Tomlins K, Manful J, Larweh P, Hammond L. Urban consumer preference and sensory evaluation of locally produced and imported rice in West Africa. Food Qual Prefer. 2005;16:79-89.

9. JICA. The Study on the Promotion of Domestic Rice in the Republic of Ghana National Development Planning Commission (NDPC) (2005), Growth and Poverty Reduction Strategy (GPRS II). 2007.

10. Andriesse W, Fresio LO. A characterization of rice growing environment in West Africa'. Agric Ecosyst Environ. 1991:33:337-95.

11. Quaye W. Food sovereignty and combating poverty and hunger in Ghana. Tailor Biotechnol. 2007, 3(2):108-201 (4466 Afr. J. Agric. Res.).

12. Starasts AM. Battling the knowledge factor: a study of farmers' information seeking learning and knowledge process with an online environment in Queensland. 2004 Unpublished Ph.D. Thesis.

13. Riesenberg LE, Gor CO. Farmers' preferences for methods of receiving information on new or innovative farming practices, Graduate Student University of Idaho 1999. Available at http://pubs.aged.tamu.edu/jae/pdf/ vol30/30-03-07.pdf.

14. Adhiguru P, Birthal PS, Kumar BG. Strengthen pluralistic agricultural information delivery systems in India. Agric Econ Res Rev. 2009. 22:71-79. Available at http://ageconsearch.umn.edu/bitstream/57382/2/5-PAdhiguru.pdf.
15. Ogboma MU. Access to agricultural information by fish farmers in Niger delta region of Nigeria. J Lib Philos Pract 2010. Available at http://www. faqs.org/periodicals/201009/2166597671.htm.

16. Daudu S, Chado SS, Igbashal AA. Agricultural information sources utilized by farmers in Benue state, Nigeria. Pub Agric Technol. 2009. 5(1):39-48. Available at http://patnsukjournal.net/Nol5No1/p5.pdf.

17. Babu SC, Glendenning CJ, Asenso-Okyere K, Govindarajan SK. Farmers' information needs and search behaviors: Case study in Tamil Nadu. India: International Food Policy Research Institute; 2011.

18. Ghana Districts Repository. Districts profiles of Ghana. 2014. Retrieved 10th November, 2014, from http://ghanadistricts.com/home/.

19. Tologbonse D, Fashola O, Obadiah M. Policy issues in meeting rice farmers agricultural information needs in Niger state. J Agric Exten. 2008. 12(2). Available at http://ajol.info/index.php/jae/article/ view/47053/33437.

20. Klair K, Boggia, Richardson ADW. The changing information needs of farmers in the U.S and Europe. Sixth joint conference on food, agriculture and the environment, Minneapolis, Minnesota August 31-Sept 2, 1998. Available at http://ageconsearch.umn.edu/bitstream/14496/1/c6klai01. pdf.

21. Denzin NK, Lincoln YS. Introduction: the discipline and practice of qualitative research. In: Denzin NK, Lincoln YS, editors. The sage hand book of qualitative research, 3rd ed. Thousand Oaks: Sage; 2005. p. 1-32.

22. Rahm MR, Huffman WE. The adoption of reduced tillage: the role of human capital and other variables. Am J Agric Econ. 1984;66(4):405-13.

23. Maddala GS. Introduction to econometrics. 3rd ed. The Atrium: Wiley; 2005. p. 318-23.

24. Asante BO, Afari-Sefa V, Sarpong DB. Determinants of small scale farmers' decision to join farmer based organizations in Ghana. Afr J Agric Res. 2011;6(10):2273-9.

25. Miyamoto K, Maruyama A, Haneishi Y, Matsumoto S, Tsuboi T, Asea G, Okello S, Takagaki M, Kikuchi M. NERICA cultivation and its yield determinants: the case of upland rice farmers in Namulonge, Central Uganda. J Agric Sci. 2012;4(6):2012.

26. GRAIN. Report on Hungry for Land Small farmers feed the world with less than a quarter of all farmland, 2014.

27. Thapa G. Smallholder farming in transforming economies of Asia and the Pacific: challenges and opportunities. Discussion Paper prepared for the side event organized during the thirty-third session of IFAD's Governing Council, 18 February 2009.

28. Lwoga ET, Ngulube P, Stilwell C. Information needs and information seeking behaviour of small-scale farmers in Tanzania. Innovation No. 40, June 2010.

29. Kock T, Harder A, Saisi P. The provision of extension services in Afghanistan: What is happening? J Int Agric Educ Exten. 2010;17(1):10.

30. Ayandiji A. Utilization of agricultural products on soybean processing by women farmers in Orire local government area of Oyo state. Unpublished M.Sc. Thesis, Department of Agricultural Extension and Rural Development, University of Ibadan, p. 3-12. 2003.

31. Aina LO, Dulle FW. Meeting the information needs of small-scale dairy farmers in Tanzania. Int Assoc Agric Lib Documen Quart Bull. 1999;44(3/4):173-6

32. Kalusopa T. The challenges of utilizing information communication technologies (ICTs) for the small-scale farmers in Zambia. Lib High Technol. 2005:23(3):414-24.

33. Dutta R. Information needs and information-seeking behaviour in developing countries: a review of the research. Int Inf Lib Rev. 2009;41(1):44-51. 